\title{
ACESSIBILIDADE NA EDUCAÇÃO A DISTÂNCIA: POSSIBILIDADES TECNOLÓGICAS PARA ESTUDANTES COM DEFICIÊNCIA
}

TAUBATÉ/SP MAIO/2018

\author{
Luciane Maria Molina Barbosa - Unitau - lucianemolina.b@gmail.com \\ Jeniffer de Souza Faria - EPTS - jeniffersouza@gmail.com \\ Mariana Aranha de Souza - Unitau - profa.maaranha@gmail.com \\ Eliana de Cássia V. de Carvalho Salgado - EPTS - elianasalg@gmail.com
}

Tipo: Relato de Experiência Inovadora (EI)

Categoria: Métodos e Tecnologias

Setor Educacional: EDUCAÇÃO SUPERIOR

\begin{abstract}
RESUMO
Diante das transformações históricas e tecnológicas vivenciadas pela sociedade moderna, a educação incorpora cenários de aceitação e respeito a diversidade. Esse trabalho tem como objetivo discorrer acerca das experiências de implementação de acessibilidade pedagógica e comunicacional nos programas de formação a distância da Universidade de Taubaté, voltadas para atender estudantes com necessidades educacionais especiais, com foco na deficiência sensorial. Para isso usamos recortes bibliográficos sobre o tema e consulta em documentos legais. Os resultados demonstram que um ambiente acessivel corrobora para o cumprimento do que prega a legislação, mas principalmente traz autonomia e pertencimento ao estudante com deficiência com vistas a qualidade do seu processo formativo.
\end{abstract}

Palavras-chave: Educação a Distância. Necessidades Educacionais Especiais. Acessibilidade. Inclusão.

\section{AGRADECIMENTOS}

A TODOS OS PROFISSIONAIS E ALUNOS QUE, DE ALGUMA FORMA, ESTIVERAM ENVOLVIDOS NO PROCESSO E CONTRIBUÍRAM PARA POSSIBILITAR MAIS E MELHORES AÇÕES EM PROL DA ACESSIBILIDADE. 


\section{Introdução}

A presença das novas tecnologias, como mediadoras de relações de ensino e aprendizagem, trazem para o cenário da educação a distância ferramentas potencializadoras que renunciam a lógica da exclusão, na medida em que se aproximam da inserção possível, de diferentes atores sociais ao ensino superior. Diante desses alcances tecnológicos, nos questionamos de que forma as pessoas com deficiência, como um dos grupos de pertencimento do movimento da escola para todos deflagrado pela Declaração de Salamanca (1994), poderão beneficiar-se da EaD? Quais as ferramentas que utilizam e que lhes dão um maior conforto no que se refere as condições específicas advindas das deficiências?

Nesse sentido, o presente trabalho tem por objetivo desvelar as potencialidades e os desafios postos para colocarmos em prática as ações planejadas e implementadas pela equipe de profissionais da Educação a Distância da Universidade de Taubaté - EaD Unitau com vistas a possibilitar a inclusão de alunos com deficiência sensorial (auditiva ou visual) nos cursos de licenciaturas e tecnológicos ofertados por esta instituição.

Para proporcionar-lhes não só o acesso, mas o sucesso e a qualidade de aprendizagem, incorporamos o paradigma da inclusão e a premissa da acessibilidade, que tem se fortalecido em nossas ações institucionais. A condição para que os ambientes e espaços sejam acessíveis e acolha essa diversidade está prevista nos documentos que regulamentam os cursos, como o Projeto Pedagógico e o Plano de Desenvolvimento Institucional. Além disso, baseamo-nos em documentos internacionais, nas legislações brasileiras e nos conceitos que remontam as diretrizes de acessibilidade em diferentes âmbitos, considerando os estudos de Dallabona (2011), Santos (2016), Oliva (2016) e Silva et al (2014).

Buscamos, então, através deste relato, situar o contexto atual de inclusão escolar, aplicando as condições mais adequadas e necessárias como ações potencializadoras do acesso, do sucesso e da permanência dos estudantes com deficiência nos nossos cursos, visando não somente o cumprimento dos dispositivos legais, mas a fundamentação e a prática deles nos cursos.

\section{Panorama sobre Acessibilidade e o Contexto Atual de Inclusão Escolar}

Nas últimas duas décadas, conceitos como exclusão e inclusão educacionais tornaramse cada vez mais recorrentes nas pesquisas, documentos oficiais e na fala de gestores e professores. Sustentados no modelo de que a inclusão de estudantes com deficiência 
representa um ganho na história da educação, vimos surgir diversos modelos baseados no conceito de deficiência, que se modificou ao longo do tempo. Da negligência ao assistencialismo, da negação ao pertencimento, os movimentos políticos e sociais implementaram novas formas de vislumbrar a educação com foco na acessibilidade. No entanto, de acordo com Oliva (2016, p. 492) "barreiras à aprendizagem e à participação ainda dificultam o cotidiano escolar dos alunos em situação de inclusão, sendo necessária a mobilização de recursos - humanos, físicos, políticos e outros - nas escolas e comunidades".

Tais barreiras trazem, nessa primeira leitura, um enfoque aos processos de ensino muito mais do que consideram as formas pelas quais os sujeitos com deficiência aprendem. Os recursos disponíveis pelos professores, por exemplo, são consequência do acesso a uma escola inclusiva e não só devem estar presentes junto ao ingresso desses alunos no convívio escolar. A acessibilidade é um movimento que antecede a chegada dos estudantes aos espaços de educação formal.

Segundo Prieto (2006 apud OLIVA 2016, p. 492)

há quatro diferentes posições em relação à educação inclusiva. Há os autores que consideram que ela já foi atingida, por entenderem que a matrícula na escola regular já caracteriza a inclusão; há os que se referem a esse modelo educacional como utópico, ou seja, impossível de ser realizado; há aqueles que defendem que ela é um processo gradual e que requer a participação de todos os atores envolvidos; e, por fim, há os que propõem a ruptura imediata com o instituído para que uma educação única atenda a todos, sem a necessidade de uma transição.

Conforme essa leitura, compreendemos que as bases pelas quais os processos inclusivos se sustentam dependem, principalmente, dos objetivos que se querem atingir com essa concepção de educação para todos, ora sustentada pelo direito ao acesso, conquista em decorrência dos avanços jurídicos, ora por uma concepção de ruptura aos modelos atuais. Soma-se a isso a descrença a um ensino que possa ao mesmo tempo ser de qualidade, percebendo a individualidade centrada no sujeito aprendiz. Porém, entendemos, a partir de Oliva (2016) que a inclusão se faz num movimento dinâmico e dialógico, com a participação do próprio estudante com deficiência para orientar as melhores práticas inclusivas com foco na acessibilidade.

Nesse sentido, o direito à acessibilidade como promotora de uma sociedade inclusiva é um direito instrumental, pois viabiliza a existência de outros direitos. Sem a acessibilidade, não se pode falar em direito à educação, à saúde, em direito ao trabalho, 
em direito ao lazer, dentre outros. Como atributo essencial do ambiente, é a acessibilidade que garante a melhoria da qualidade de vida das pessoas, possibilitandoIhes participação e inclusão (SANTOS, 2016). A acessibilidade, portanto, funciona para fortalecer o processo inclusivo, muito mais do que a quebra de uma barreira física.

Numa perspectiva histórica segundo Santos (2016) o termo acessibilidade originou-se na década de 1940, para designar a condição de acesso das pessoas com incapacidades funcionais atreladas ao surgimento dos serviços de reabilitação física e profissional. Ao longo do tempo esta definição foi ampliada e, por conseguinte, a nosso ver, evoluiu. Conforme podemos conferir no Decreto ํㅜ 5.296/04 que assim define o termo acessibilidade como condição para utilização, com segurança e autonomia, total ou assistida, dos espaços, mobiliários e equipamentos urbanos, das edificações, dos serviços de transporte e dos dispositivos, sistemas e meios de comunicação e informação, por pessoa portadora de deficiência ou com mobilidade reduzida. (BRASIL, 2004).

O decreto acima regulamentou o que já estava estabelecido na Lei 10.098/00, que deu o direito as pessoas com deficiência a supressão de barreiras físicas, arquitetônicas de informação e educação, o que implica na adequação dos meios que proporcionem a essas pessoas exercerem as mesmas atividades dos demais.

Mais recentemente, a Lei Federal 13.146/15, denominada Lei Brasileira da Inclusão da Pessoa com Deficiência (BRASIL, 2015), também especifica a acessibilidade e a eliminação de barreiras para o desenvolvimento e a participação plena das pessoas com deficiência, indicando que as incapacidades decorrem, em especial, da não adaptação razoável a esses sujeitos. (BRASIL, 2015).

Para Dallabona (2011), no que se refere ao direito à inclusão, as instituições de ensino, em especial as universidades, também devem estar adequadas às normas de acessibilidade, oportunizando que as pessoas com necessidades educacionais especiais exerçam seu direito de cidadania.

Nesse contexto, há várias orientações para incluir estudantes com deficiência nas instituições de ensino superior (IES), a qual podemos destacar desde as que solicitavam a viabilização de condições de acesso aos candidatos com deficiências em seus concursos vestibulares (Aviso Circular n² 277 MEC/GM5, 1996), às Portarias, Decretos, Resoluções, Programas e Políticas que estabelecem uma série de requisitos relacionados à acessibilidade para a pessoa com deficiência[1]. 
Nesse contexto, podemos citar a Política Nacional de Educação Especial na Perspectiva da Educação Inclusiva que evidenciou a transversalidade da educação especial no ensino superior, a qual deve ocorrer por meio de ações que fortaleçam o acesso, a permanência e a participação dos alunos. Para tal, o planejamento e a organização de recursos e serviços para a viabilização da acessibilidade arquitetônica, das comunicações, dos sistemas de informação, dos materiais didáticos e pedagógicos devem ser disponibilizados nos processos seletivos e no desenvolvimento de todas as atividades que envolvam o ensino, a pesquisa e a extensão (BRASIL, 2008).

Em linhas gerais, vemos que, mesmo por força dos documentos legais, a universidade cada vez mais está se adaptando para suprir as necessidades dos estudantes que possuem algum tipo de deficiência. Nesse sentido, reiteramos ainda sobre o fato de que este público deve ser ouvido para que a universidade possa melhorar as condições de ensino e aprendizagem (DALLABONA, 2011).

A acessibilidade ainda é um tema pouco difundido, apesar de sua inegável relevância para a mudança de paradigma entre integração e inclusão. Considerando que a acessibilidade gera resultados sociais positivos e contribui para o desenvolvimento inclusivo e sustentável, sua implementação, mesmo que gradual, é fundamental, dependendo, principalmente, de mudanças culturais e atitudinais.

\section{Metodologia}

A elaboração desse relato foi pautada nas premissas metodológicas da revisão de literatura, articulada a um estudo descritivo realizado a partir das experiências profissionais dos autores desse trabalho, que colaboraram no processo de implementação de recursos de tecnologia assistiva no Ambiente Virtual de Aprendizagem, com destaque para a docente que por vivenciar situações da deficiência visual, mantém larga experiência com ferramentas tecnológicas inclusivas para pessoas cegas ou com baixa visão. Soma-se a isso, a experiência profissional da docente que, como intérprete de Libras, reconhece a identidade surda como uma característica a ser validada na tomada de decisões para propor os requisitos de acessibilidade.

\section{Acessibilidade Comunicacional na Educação a Distância}

O Ambiente Virtual de Aprendizagem (AVA) se constitui em ferramenta chave para os sistemas educacionais a distância, pois permite o trabalho formativo, que se desenvolve no e com este ambiente. De acordo com Silva et al (2014) os AVA provocaram mudanças e reflexões positivas sobre o processo educacional como um todo, pois estes 
permitem novas possibilidades e "espaços" para promover a aprendizagem e a "dialogicidade por meio dos seus diversos recursos de interação e comunicação" (p.223).

Dentre os diferentes modelos disponíveis, a plataforma Moodle se tornou a mais comum na atualidade. Acreditamos que o motivo seja pelo fato de ser um ambiente gratuito e com código aberto, ou seja, passível de customização, e que disponibiliza recursos e atividades permitindo "diferentes maneiras de se comunicar, trocar informações e divulgar conhecimento" conforme aponta Silva et al (2014, p.216), potencializando novas práticas pedagógicas.

Em contrapartida, para Silva et al. (2014), as interfaces responsáveis pela exibição do conteúdo em tais ambientes, em sua maioria, não seguem diretrizes para acessibilidade devido a forma como os conteúdos são disponibilizados aos estudantes. As informações disponíveis em um AVA, em um primeiro momento, podem nos parecer organizadas, claras, objetivas, destacadas, ou seja, de fácil acesso a todo e qualquer usuário. No entanto, ao considerarmos as limitações visuais (pessoas com baixa visão ou cegueira) ou auditivas (pessoas surdas), passamos a conhecer o desafio que deveríamos enfrentar relacionado a acessibilidade no nosso AVA frente a chegada dos estudantes com deficiência auditiva e deficiência visual em nossa instituição, considerando também a presença de uma professora cega, atuando na tutoria eletrônica.

Nesse sentido, duas frentes macro de trabalho foram acionadas de forma articulada: a pedagógica e a tecnológica. Ambos representados por dois setores da nossa instituição de ensino. O setor pedagógico composto pelo Grupo de Apoio à Acessibilidade Estudantil (GAAE), Coordenador e equipe dos Objetos de Aprendizagem, Coordenadores de Curso, Docentes de Apoio e Tutor; e o setor do Tecnológico composto pelo TI (Tecnologias de Informação e Comunicação), DI (Designer Instrucional) e Áudio Visual.

Logo, para validar o significado da palavra acessibilidade apresentados na primeira parte deste relato, entendemos ser necessário instituir um conjunto de medidas que possibilitem o acesso, a participação e o pertencimento, ou seja, condições favoráveis nos ambientes que permitam a pessoa com deficiência ter segurança e autonomia em seus estudos.

Frente às limitações deste texto optamos por relatar as mudanças instituídas pela equipe tecnológica em diálogo com as docentes especialistas em deficiência visual e auditiva citadas anteriormente. O papel delas foi fundamental para implementarmos 
ações que efetivamente contribuíssem com a aprendizagem dos alunos e não apenas para atender as exigências postas na legislação sobre acessibilidade.

A primeira ação que ocorreu em âmbito tecnológico, consistiu na pesquisa, nos testes e na implementação de barras de acessibilidade, aplicativos, plug-ins compatíveis com o Moodle para serem incorporados à plataforma. Além disso, buscou-se conhecer modelos de outras plataformas acessíveis elaboradas por diferentes IES. Essa investigação permitiu tomadas de decisão que levasse em conta as premissas: o que queríamos, o que precisávamos e o que era possível realizar no contexto e cenário atual que se encontra a Universidade.

No decorrer desse processo de investigação, a professora da IES com deficiência visual, também usuária e pesquisadora de modelos de acessibilidade nessa plataforma, realizou algumas intervenções como colaboradora junto a equipe de $\mathrm{TI}$, com o objetivo de testar, validar ou propor melhores soluções. Dentre elas foram consideradas a descrição de algumas teclas de atalhos que funcionam nos leitores de tela para pessoas com deficiência visual. Além de testes com aplicativos de acessibilidade gratuitos para conversão de textos PDF no formato imagem para texto editável, a fim de que pudessem ser decodificados em áudio ou ampliados conforme tamanho de fonte adequado às necessidades visuais dos sujeitos investigados. A disposição dos objetos na plataforma e a possibilidade da descrição de imagens também foram foco da nossa atenção inicial, embora o segundo elemento ainda esteja em construção. Todas as ferramentas implantadas, o funcionamento das teclas de atalho, a organização dos menus de acessibilidade e a pertinência dos usos desses recursos dentro de cada navegador, foram analisadas e validadas. Os feedbacks dos alunos com baixa visão que utilizam a plataforma com recursos de ampliação e contraste também foram, e ainda continuam sendo, considerados nesse processo de adaptação.

A professora intérprete e especialista em deficiência auditiva também contribuiu com sugestões de aplicativos e na produção da janela de libras em vídeo aulas, processo que está em andamento e em crescente expansão para atender todos os cursos gradativamente. Além disso, seu diálogo cumpriu a tarefa de mostrar de que forma as pessoas surdas são beneficiadas com a tradução para Libras, como funcionam os avatares na tradução literal e as falhas de uma interpretação mecânica mediada pelos plugins. Pontuou junto a equipe de TI algumas necessidades de alteração estrutural das ferramentas textuais nos menus, o que mostrou ser imprescindível para que os estudantes surdos consigam navegar com autonomia.

A partir dessas ações iniciais, considerando o planejamento, a pesquisa e os testes de 
validação, a equipe do $\mathrm{TI}$ instalou e implementou as melhores ferramentas para serem aplicadas dentro da realidade atual de instalação do Moodle e condições financeiras, de tempo e gestão de softwares. Todos estavam dispostos a aprender, perguntar e dialogar, fazendo as alterações e instalações. Foram receptivos a todas as manifestações, sugestões e feedbacks encaminhados, pois de posse dos dados poderiam encontrar as melhores soluções mediante o conhecimento técnico acumulado dentro das suas áreas de formação.

Percebemos, enquanto envolvidos com o processo, que as soluções encontradas ficaram coerentes e positivas para as falhas de acessibilidade e de usabilidade presentes inicialmente na plataforma. Dentre estas soluções destacamos:

A implementação de uma barra com recursos de ampliação de letras, contraste de cores, leitura de texto selecionado e avatar de Libras, o que traz soluções para uma significativa parte do público/estudantes com deficiência, além de atender a legislação.

Também foram inseridos dois menus de acessibilidade, um na página inicial e outro, na sala Web, agrupando links mais utilizados que podem ser acessados por teclas de atalho. Do ponto de vista da professora especialista e deficiente visual, talvez, esta mudança tenha sido a mais impactante para seu trabalho como tutora, pois reduziu significativamente o tempo que utiliza para cada tarefa executada na plataforma. Entretanto, vale ressaltar que todas as implementações servem tanto para tutores quanto para alunos com deficiência que já participam ou que venham a participar da EaD nessa IES.

Outra ação que consideramos importante nesse processo foi a criação de um espaço com informações sobre acessibilidade principalmente para os alunos, que pode ser acessado num link disponível na página inicial da plataforma. Embora já tenhamos vislumbrado muitos avanços, em pouco mais de quatro meses, o processo ainda permanece em constante movimento. Nesse sentido, de todas as possibilidades ainda temos alguns desafios.

Detectamos a dificuldade técnica de acesso a plataforma de forma confortável para os estudantes com deficiência visual, especificamente, em dispositivos móveis e no APP oficial do Moodle para celulares e tabletes. A respeito do conteúdo, algumas questões estão sendo exaustivamente trabalhadas, como a disponibilização da janela de Libras nas videoaulas; a audiodescrição nas imagens do material didático e possivelmente nas videoaulas, condição que depende da formação de um profissional interno; estudo e planejamento sobre uma versão dos materiais de leitura disponibilizados pelo recurso 
livro em html direto na plataforma, como texto alternativo aos PDF. Nesse caso o conteúdo poderá ser lido e ampliado pelos próprios recursos da barra de acessibilidade implementada na plataforma, além de outras ações pontuais.

Diante do exposto, podemos inferir que se constitui um desafio aos produtores de conteúdo na EaD diminuir as limitações de acesso aos recursos e informações disponíveis no AVA, para incorporar no processo formativo práticas acessíveis por meio das tecnologias ou adaptações ao material físico, pois nem sempre os que pensam o formato do curso buscam alternativas para superar esta perspectiva restrita. (SILVA et al, 2014).

\section{Considerações Finais}

Em suma, podemos perceber que as adequações mais impactantes são aquelas que envolvem uma forma diferente de navegar e de apropriação dos conteúdos por linguagens diferentes, seja por Libras, seja pelo uso dos leitores de tela. Quando esses pontos estão em equilíbrio, certamente todos os demais já foram solucionados.

Entretanto, cabe destacar que a acessibilidade não inclui apenas adequações do ambiente para leitores de tela, letras ampliadas, contraste e Libras, mas são adequações que provocam melhoria na navegabilidade para todos, independente de deficiências mais ou menos visíveis.

Mediante tudo o que foi feito pela equipe de $\mathrm{Tl}$, embora não sejam apenas decisões políticas, são ações que sustentarão todos os movimentos pedagógicos, de currículo, de acolhimento, de percepção do outro pelo olhar da diversidade.

Neste sentido, o processo formativo deve abarcar a todos, revendo as ações para a mobilização de saberes e habilidades e, com isso, contribuindo na construção de uma nova temática educativa. $\mathrm{O}$ grande desafio é levar a inclusão à maioria dos estudantes, entender que o principal propósito é facilitar a aprendizagem e a adequação metodológica com finalidades para acessibilidade.

\section{Referências}

BRASIL. Declaração de Salamanca. Brasília: UNESCO, 1994.

Ministério da Educação/Gabinete do Ministro (GM). Aviso Circular n 277.

Brasília: MEC/GM, 1996. 


\section{Política Nacional de Educação Especial na Perspectiva da Educação}

Inclusiva. Brasília: MEC/ SEESP, 2008.

Portaria Ministerial n. 1.679/99. Brasília: MEC, 1999.

Lei 13.146, de 06 de julho de 2015. Lei Brasileira de Inclusão.

Decreto n. 5.296, 2 de dezembro de 2004. Regulamenta as Leis $N^{\circ} 10.048$, de 8 de novembro de 2000, e a Lei $N^{\circ} 10.098$, de 19 de dezembro de 2000. Brasília, DF, 2004.

DALLABONA, Kátia G. Inclusão de Deficientes Visuais no Curso Superior na Educação a Distância. Anais do XVII Congresso da Associação Brasileira de Educação a Distância. 2011. Disponível em: . Acesso em: 07 mai. 2018.

OLIVA, D.V. Barreiras e recursos à aprendizagem e à participação de alunos em situação de inclusão. Psicol. USP, São Paulo, v. 27, n. 3, p. 492-502, Dez. 2016 . Disponível em: . Acesso em: 21 jul. 2017.

SANTOS, W. Deficiência como restrição de participação social: desafios para avaliação a partir da Lei Brasileira de Inclusão. Ciênc. saúde coletiva, Rio de Janeiro , v. 21, n. 10, p. 3007-3015, Oct. 2016 . Disponível em: . Acesso em: 07 mai 2018.

SILVA, Danilo G. da et al. Um olhar interno pra os recursos do Moodle: algumas considerações sobre participação e interação. In: Reali Al, M. de M.R \& Mill, Daniel. Educação a distância e tecnologias digitais: reflexões sobre sujeitos, saberes, contextos e processos. São Carlos: EdUFSCar, 2014.

[1] Portaria n. 1.679/99, Decreto nํ 3.298/99, Portaria no 3.284/2003, NBR 9.050/04, Programa de Acessibilidade na Educação Superior e Decreto Federal 5.626, ambos em 2005 subsidiados pelo Ministério da Educação. Lei Brasileira de Inclusão, 2015, Resolução nº 283/16, etc. 